\title{
EVENTOS CLIMÁTICOS DE RISCOS HIDROMETEOROLÓGICOS NA CIDADE DE ARARAQUARA
}

\section{CLIMATE EVENTS OF HYDROMETEOROLOGICAL'S RISK FROM ARARAQUARA}

\section{Leonardo Parize', Anderson Manzoli ${ }^{2}$, Pedro Fernando Campos Caballero ${ }^{3}$}

\author{
${ }^{1}$ Estudante de Graduação Eng. Ambiental. Faculdades Integradas de Araraquara \\ (FIAR).e-mail: lparize@gmail.com \\ ${ }^{2}$ Engenheiro Civil. Prof. Dr. Faculdades Integradas de Araraquara (FIAR). e-mail: \\ amanzoli@sc.usp.br \\ ${ }^{3}$ Pedagogo. Prof. M.Sc e Coordenador do Grupo de Pesquisa de Riscos Ambientais \\ (GPRA) Faculdades Integradas de Araraquara (FIAR). e-mail: \\ pedrocaballero@logatti.edu.br
}

\begin{abstract}
Diversos fatores podem conduzir as sociedades ao desenvolvimento de cidades instáveis, desse modo estas se tornam vulneráveis no sistema ambiental, dentre eles: variabilidade climática, exclusão social, pobreza, crescimento desordenado da população, uso e ocupação do solo irregular entre outros agentes determinantes. Os municípios do Brasil em sua maioria apresentam uma alta vulnerabilidade em algumas áreas geográficas por diversas causas conhecidas, sejam antropogênicas, naturais, induzidas e mistas, mas não são levadas em conta pelos atores envolvidos na gestão dos riscos ambientais. Os acidentes causados por estes processos, que acabam sendo desastres, têm apresentado no Brasil um número elevado de vítimas fatais e perdas de ordem econômico ao patrimônio superior a 60 milhões de reais. O presente trabalho teve como objetivo geral levantar dados referentes às enchentes e inundações, através do mapeamento das áreas de risco hidrometeorológico. O ponto crítico destacado na cidade de Araraquara é: Avenida Maria Antonia Carvalho de Oliveira com Rua Domingos Zanin, na região do bairro Arangá, próximo ao Terminal Rodoviário. Portanto, a proposta metodológica para a elaboração do mapa de risco prevê o atendimento às necessidades da comunidade de Araraquara, no que se relaciona ao planejamento ambiental e identificação dos riscos na área urbana, visando à melhoria na proteção da qualidade de vida ambiental.
\end{abstract}

Palavras-chave: Riscos hidrometeorológicos. Vulnerabilidade. Enchentes. Inundações. Desastres naturais.

\footnotetext{
ABSTRACT

Several factors may lead societies to development of unstable cities, thus they become vulnerable into environmental system, such as: climate variability, social exclusion, poverty, uncontrolled
} 
population growth, irregular land use and occupation and other determinants agents. The municipalities in Brazil, mostly have a high vulnerability in some areas for several known causes, such as anthropogenic, natural, induced and mixed, but are not taken into account by actors involved in the management of environmental risks The accidents caused by these processes, which are eventually disasters, have shown in Brazil a high number of fatal victims and losses of economic nature higher than 60 million reais. This study aimed to collect data related to floods, through the mapping of hydrometeorological risk. The critical areas highlighted in the city of Araraquara is: Avenida Maria Antonia Carvalho de Oliveira, Rua Domingos Zanin, in Arangá neighborhood next to the Bus Terminal. Hence, the methodology for the elaboration of the risk map predicts the treatments to the needs of the Araraquara community, as it relates to environmental planning and hazards identification in the urban area, aiming to improve the protection of the environmental and quality of life.

Keywords: Hydrometeorological hazards. Vulnerability. Floods. Disasters natural.

\section{INTRODUÇÃO}

Os desastres naturais constituem um tema cada vez mais presente no cotidiano das pessoas, independentemente destas residirem ou não em áreas de risco. Ainda que em um primeiro momento o termo nos leve a associá-lo com terremotos, tsunamis, erupções vulcânicas, ciclones e furacões, os Desastres Naturais contemplam, também, processos e fenômenos mais localizados tais como deslizamentos, inundações, subsidências e erosão, que podem ocorrer naturalmente ou induzidos pelo homem.

Os fenômenos naturais por si só não são um problema, mas passam a ser quando atingem uma parcela da sociedade, tornando-se desastres naturais.

Eventos climáticos, crescimento exacerbado da população, uso descontrolado dos solos, pobreza, injustiça social, incentivos ao consumismo exagerado, entre outros fatores, conduzem as sociedades para um desenvolvimento de cidades instáveis, que são consideradas vulneráveis no sistema ambiental.

De acordo com Todini (1999), os danos ocasionados pelas inundações deverão aumentar significativamente através dos grandes riscos inerentes das áreas urbanizadas e devido às mudanças climáticas. No Estado de Santa Catarina, segundo Herrmann et al. (2007), entre 2000 e 2003, as inundações causaram prejuízos de aproximadamente US\$ 255.128.953,00.

Diante disto, faz-se necessário elaborar medidas preventivas e mitigadoras que possam diminuir os impactos destes eventos e os gastos pós desastres.

No Brasil, os desastres naturais são tratados de forma segmentada entre os diversos setores da sociedade. De acordo com Kobiyama et al (2006), nos últimos anos ocorreu uma intensificação dos prejuízos causados por estes fenômenos devido ao mau planejamento urbano.

Os maiores problemas e danos encontrados no país atualmente relacionados com desastres naturais acontecem em função aos eventos climáticos destacados como riscos hidrometeorológicos.

O risco hidrometeorológico "é um evento natural, ocorrido em caso de chuva de grande proporção que afeta uma parcela da sociedade. Serve como exemplo deste tipo de risco as enchentes e inundações".

A Secretaria Nacional de Defesa Civil do Brasil (2009) discorre sobre um estudo da Organização das Nações Unidas (ONU), no qual a relação de prevenção e gastos pós desastre no Brasil é de U\$ $1 / 7$, ou seja, um dólar para prevenção e sete dólares para os gastos pós desastres. Para Goerl (2010), os prejuízos com os desastres naturais são de aproximadamente 60 milhões de reais no Brasil. 
O trabalho realizado por Canholi (2005) elenca os principais problemas relacionados com a infra-estrutura e a urbanização nos países da América Latina, que são: Grande concentração populacional em pequena área; deficiência em transportes; falta de saneamento básico; além das inundações. Isso torna as condições ambientais inadequadas, a saúde pública e a qualidade de vida são prejudicadas e dificulta o desenvolvimento das cidades. Nesse trabalho, destacou-se o aumento da periferia das cidades ocorrido na ausência de controle pela migração rural em busca de emprego, atingindo áreas sem estrutura para suporte de loteamento, como falta de drenagem urbana, transporte, esgoto e coleta de resíduos sólidos.

Tanto o planejamento como a gestão urbana são ferramentas usadas para pôr em prática uma reformulação na infra-estrutura da cidade. O planejamento visa preparar as cidades para o futuro, estabelecer critérios de prevenção e controle. Já as gestões urbanas têm a preocupação de exercer o trabalho atual, solucionar os problemas atuais.

$\mathrm{O}$ principal objetivo deste trabalho foi levantar os dados referentes às enchentes e inundações, através do mapeamento das áreas de riscos, realizado no ano de 2009 pelo GRUPO DE PESQUISA DE RISCO AMBIENTAL (GRPA) das Faculdades Integradas de Araraquara, onde foram analisados os cenários urbanos, cujos riscos hidrometeorológicos causaram problemas no município de Araraquara.

Como objetivo específico, pretendeu-se qualificar os possíveis riscos e consequências das enchentes.

\section{MATERIAIS E MÉTODOS}

Para atender o objetivo deste trabalho, foi utilizada parte dos dados adquirida pelo Grupo de Pesquisa de Risco Ambiental (GPRA) das Faculdades Integradas de Araraquara, na qual o GPRA adquiriu as informações sobre os riscos hidrometeorológicos.

Foram localizados 11 pontos críticos com problemas de inundações, enchentes e alagamentos, através do mapeamento das áreas de riscos que o GPRA levantou no ano de 2009.

Embasado no levantamento bibliográfico, foi proposto um banco de dados com os possíveis locais atingidos por problemas ambientais (riscos hidrometeorológicos), através de uma listagem que contem algumas informações, como as causas prováveis e características de cada local.

Por meio dos levantamentos coletados em cada área identificada anteriormente, foram feitas visitas técnicas, a fim de que fosse estudado o controle das cheias, nos meses de agosto a outubro. Com isso, foram feitas medições sobre os dados em dias de estiagem e de estiagem com chuva, no Córrego do Ouro próximo à região do terminal rodoviário.

Para este trabalho, foi dada uma maior atenção às enchentes, pois o volume da água é maior que o das inundações (alagamentos), tendo um alto grau de magnitude.

A velocidade foi calculada a uma distância de 30 metros, em três tentativas, com o intuito de se obter uma média. O flutuador foi colocado no centro do córrego e, com uma trena de 50 metros, foram medidos 30 metros para separar a distância e obter a velocidade.

Para o cálculo das vazões, foi utilizado o Método $I-P a i-W u$, dado pela equação 1 (DAEE, 94), que constitui-se num aprimoramento do Método Racional, podendo ser aplicado para bacias com áreas de drenagem de 2 a $200 \mathrm{Km}^{2}$.

Com o propósito de se ter a chuva de projeto primeiramente, definiram-se as precipitações máximas, que foram feitas a partir da Equação de Chuvas da Cidade de Araraquara.

Após isso, realizou-se a verificação da capacidade de vazão, em duas áreas de seções do canal do Córrego do Ouro.

Com isso foi realizada análise completa do sistema de escoamento superficial existente na área urbana, permitindo apontar possíveis soluções para o problema. 


$$
Q=0,278 . C . i . A^{0,9} \cdot K
$$

Sendo que:

$\mathrm{Q}=\operatorname{Vazão}\left(\mathrm{m}^{3} / \mathrm{s}\right)$;

$\mathrm{C}=$ Coeficiente de Escoamento Superficial;

$\mathrm{i}=$ Intensidade de chuva $(\mathrm{mm} / \mathrm{h})$;

$\mathrm{A}=$ área de Contribuição da Bacia Hidrográfica $\left(\mathrm{km}^{2}\right)$;

$\mathrm{K}=$ Coeficiente de distribuição espacial da chuva.

A vazão de pico é dada pela equação 2 (DAEE,94):

$$
Q \text { pico }=1,10 . Q
$$

Sendo que:

Qpico $=$ Vazão de pico $\left(\mathrm{m}^{3} / \mathrm{s}\right)$.

Para que fosse feita uma definição dos parâmetros de chuvas intensas da região abrangida pela bacia hidrográfica do córrego em estudo, utilizou-se equação de chuvas definida por Francisco Martinez Júnior e Nelson Luiz Goi Magni e apresentada na publicação "Equações de Chuvas Intensas do Estado de São Paulo" edição revisada em outubro/1999.

A intensidade da Chuva Crítica $\left(i_{t}, \mathrm{~T}\right)$, no Município de Araraquara, empregou-se valores entre $105 \leq \mathrm{t} \leq 1440$ a (equação 3 ).

$$
i_{i, T R}=32,4618(t+15)^{-0,8684}+18,4683 \cdot(t+15)^{-0,9984} \cdot\left[-0,4772-0,9010 \cdot \ln \cdot \ln \left(\operatorname{Tr}_{T r-1}\right)\right\rfloor
$$

Sendo que:

$\mathrm{i}$ = intensidade da chuva, correspondente à duração "t" e período de retorno " $\mathrm{T}$ ” em $\mathrm{mm} / \mathrm{min}$

$\mathrm{t}=$ Duração da chuva, em minutos

Período de Retorno $\left(\mathrm{T}_{\mathrm{r}}\right)$ em anos

$\mathrm{i}_{\mathrm{t}, \mathrm{T}}=\mathrm{mm} / \mathrm{h}$

A validação do projeto foi dada a partir da identificação dos riscos hidrometeorológicos em cada ponto e do tipo de problema apresentado na região, sendo que a identificação pôde ser apontada como enchente ou inundação.

A intenção é disponibilizar o mapa elaborado para Prefeitura e aos Órgãos Públicos, com o intuito de proteger e assegurar a vida da população que vive no local.

\section{RESULTADOS E DISCUSSÃO}

De todos os pontos estudados verificou-se a existência deles com problemas de 9 inundações e 2, de enchentes. 
Porém neste trabalho será abordado apenas um risco hidrometeorológico caracterizado como enchente, localizado na região do Córrego do Rio do Ouro, próximo ao Terminal Rodoviário.

Este ponto de enchente é o local que causa maiores preocupações; pois necessitam de investimentos pesados, obras de engenharia mais estruturada e um período de tempo maior. Essas mitigações são enquadradas como medidas estruturais.

Para estudar melhor os casos foram estipulados três anos de retorno (50, 100 e 200 anos) através de modelagens matemáticas já representadas na metodologia, conforme a Tabela 1 demonstra.

Tabela 1 - Comparação das vazões de pico em relação ao tempo de retorno

\begin{tabular}{|c|c|c|c|}
\hline $\begin{array}{c}\text { Tempo de } \\
\text { retorno (anos) }\end{array}$ & 50 & 100 & 200 \\
\hline $\begin{array}{c}\text { Intensidade da } \\
\text { Chuva (mm/h) }\end{array}$ & 28 & 34 & 40 \\
\hline $\begin{array}{c}\text { Duração da } \\
\text { chuva em } \\
\text { (min) }\end{array}$ & 600 & 600 & 600 \\
\hline $\begin{array}{c}\text { Vazões de pico } \\
\left(\mathrm{m}^{3} / \mathrm{s}\right)\end{array}$ & 11,17 & 13,56 & 14,5 \\
\hline
\end{tabular}

Este trabalho teve maior enfoque nos riscos de enchentes, por se tratar de maiores proporções para engenharia. Os outros problemas apresentados, basicamente, são considerados obras de pequeno porte, como limpeza das galerias pluviais, redimensionamento das bocas de lobo e aumento da quantidade de bocas de lobo para captar a água das chuvas.

Caracterizado o ponto de Enchente na Avenida Maria Antônia C. de Oliveira, é posta em seguida a Tabela 2, que representa o estudo no Córrego Rio do Ouro que percorre uma parte da cidade de Araraquara.

Tabela 2- As Características da Bacia Hidrográfica do Córrego Ribeirão do Ouro

\begin{tabular}{|l|c|}
\hline Área total da Bacia de Contribuição & $36 \mathrm{~km}^{2}$ \\
\hline Perímetro & $22,94 \mathbf{~ k m}$ \\
\hline Ordem & 3 \\
\hline Classe & 4 \\
\hline Comprimento do Talvegue & $14,3 \mathrm{~km}$ \\
\hline Comprimento do trecho estudado & 425 \\
\hline Densidade de Drenagem & $1,53 \mathrm{~km} / \mathrm{km}^{2}$ \\
\hline Tempo de Concentração & $406,10 \mathrm{horas}$ \\
\hline Fator de Forma (F) & 0,176 \\
\hline Coeficiente Volumétrico de Escoamento Supercifial (C2) - Adotado & 0,7 \\
\hline $\mathrm{I}_{\mathrm{t}, \mathrm{T}}$ & $36 \mathrm{~mm} / \mathrm{h}$ \\
\hline Coef. De Distribuição Espacial da Chuva (K) & 0,08 \\
\hline Coef. De Forma (C1) & 1,836 \\
\hline Coef. De Escoamento Superciail @ & 0,648 \\
\hline Cálculo da Vazão de Pico (Qp) & $14,36 \mathrm{~m}^{3} / \mathrm{s}$ \\
\hline
\end{tabular}


A vazão de pico montante é de $2,94 \mathrm{~m}^{3} / \mathrm{s}$ na época de estiagem. Já a vazão de pico a jusante será de $3,8 \mathrm{~m}^{3} / \mathrm{s}$. Essas vazões foram medidas em campo, a fim de obter os valores das vazões nos períodos de estiagem.

Considerando a intensidade da chuva de $36 \mathrm{~mm} / \mathrm{h}$ (intensidade da chuva obtida através das usinas de cana de açúcar e álcool da região de Araraquara), com a área da bacia de $36 \mathrm{~km}^{2}$, o coeficiente volumétrico de escoamento de 0,648 e o coeficiente de distribuição espacial da chuva 0,08 , foi obtido como resultado, dado pela equação de $I-P a i-W u$, a vazão de $13,05 \mathrm{~m}^{3} / \mathrm{s}$ e a vazão de pico foi de $14,36 \mathrm{~m}^{3} / \mathrm{s}$.

Na ponte à jusante do local de estudo há uma régua limnimétrica para registrar a altura do nível da água do corpo hídrico. Este instrumento foi colocado pela Defesa Civil do Município de Araraquara, por ser considerado um local de risco hidrometeorológico, conforme ilustra a Figura 1.

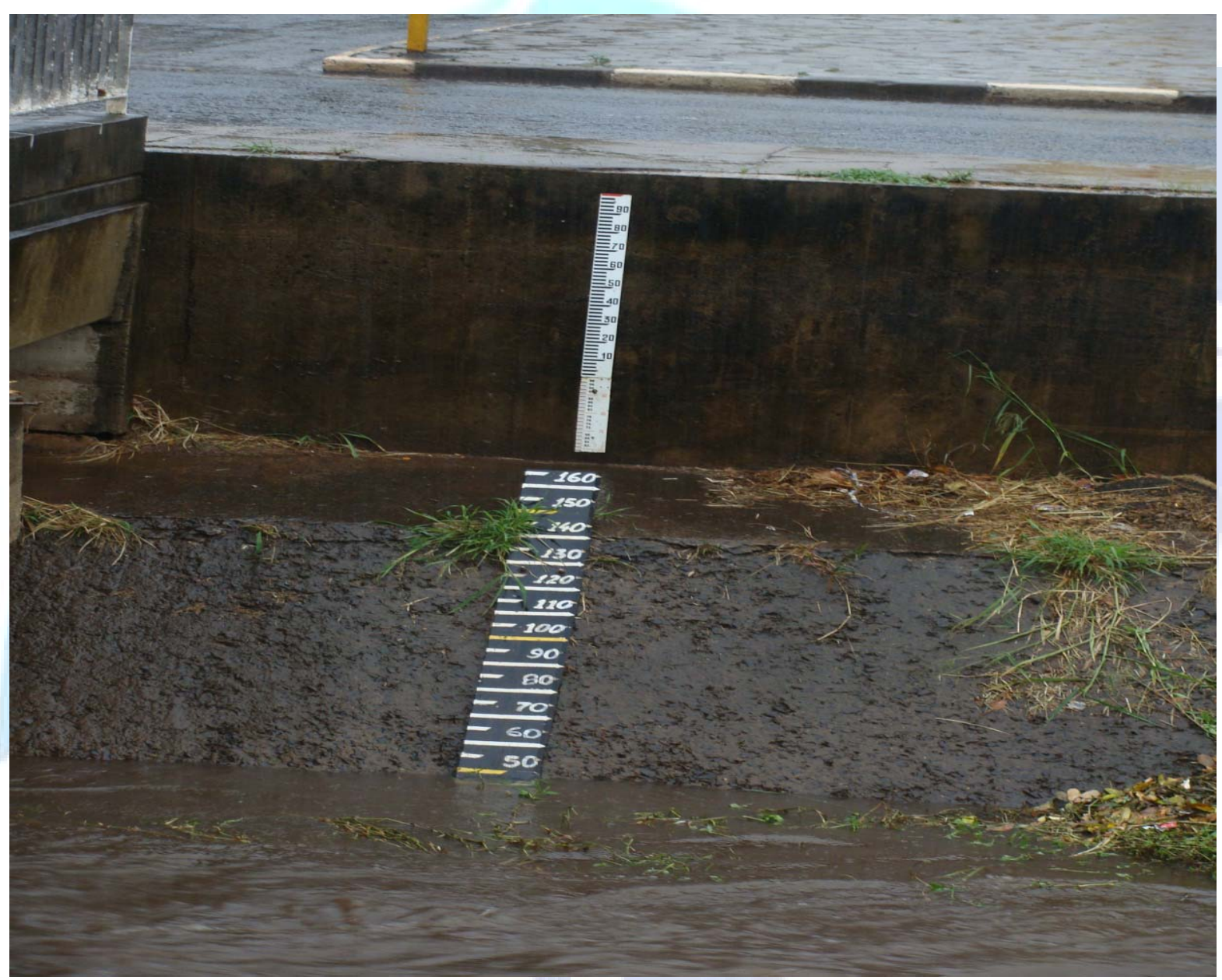

Figura 1. Régua limnimétrica de medição do nível d'água, colocado pela Defesa Civil de Araraquara. Fonte: Parize, 2010.

Comparando as vazões de pico de $14,36 \mathrm{~m}^{3} / \mathrm{s}$ com a vazão do dia 26 de setembro de 2010 , obtêm-se os valores de vazões de $11,17 \mathrm{~m}^{3} / \mathrm{s}, 13,56 \mathrm{~m}^{3} / \mathrm{s}$ e $14,50 \mathrm{~m}^{3} / \mathrm{s}$, e os tempos de retorno já mencionados, a saber, 50, 100 e 200 anos, considerando a duração da chuva de 10 horas (600 minutos), conforme registrado a informação informal pelas usinas da região de Araraquara. 
Em destaque, a Figura 2 exibe a área de contribuição, pela linha vermelha, e o local de risco hidrometeorológico (risco de enchente) marcado pela cor azul. A cor roxa sobreleva o comprimento do talvegue.

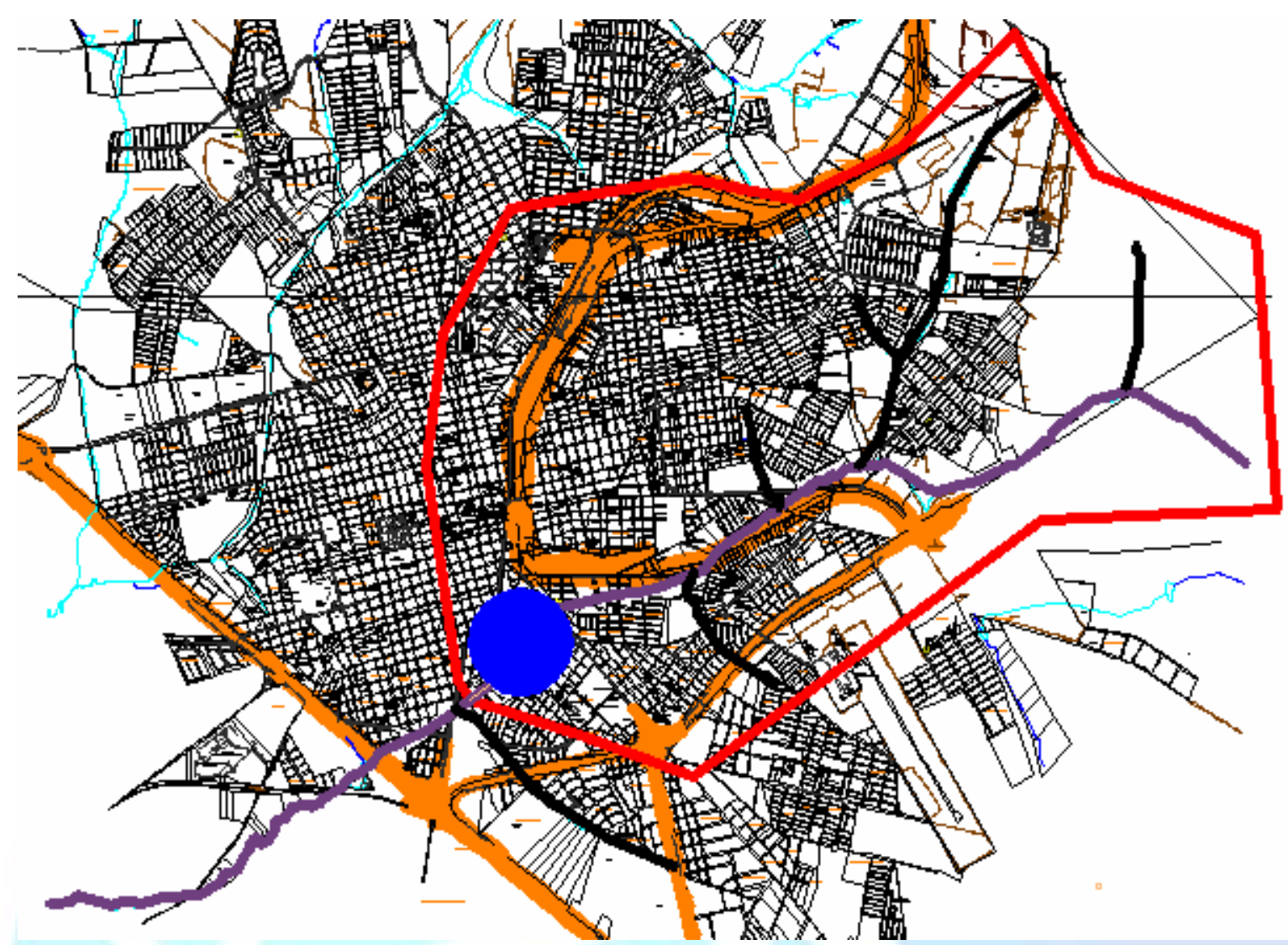

Figura 2. Representa a área de contribuição da bacia e o tamanho do comprimento do talvegue. Fonte: Parize, 2010.

A Figura 3 apresenta as seções 1 e 2, para a seção 1, a área aproximada do perfil molhado é de $1,95 \mathrm{~m}^{2}$. Já para a seção 2 , não foi possível realizar o cálculo para encontrar a área do perfil molhado, pois, o córrego está enterrado. Não havia acessibilidade para coletar os resultados da área molhada do Córrego da Servidão. 


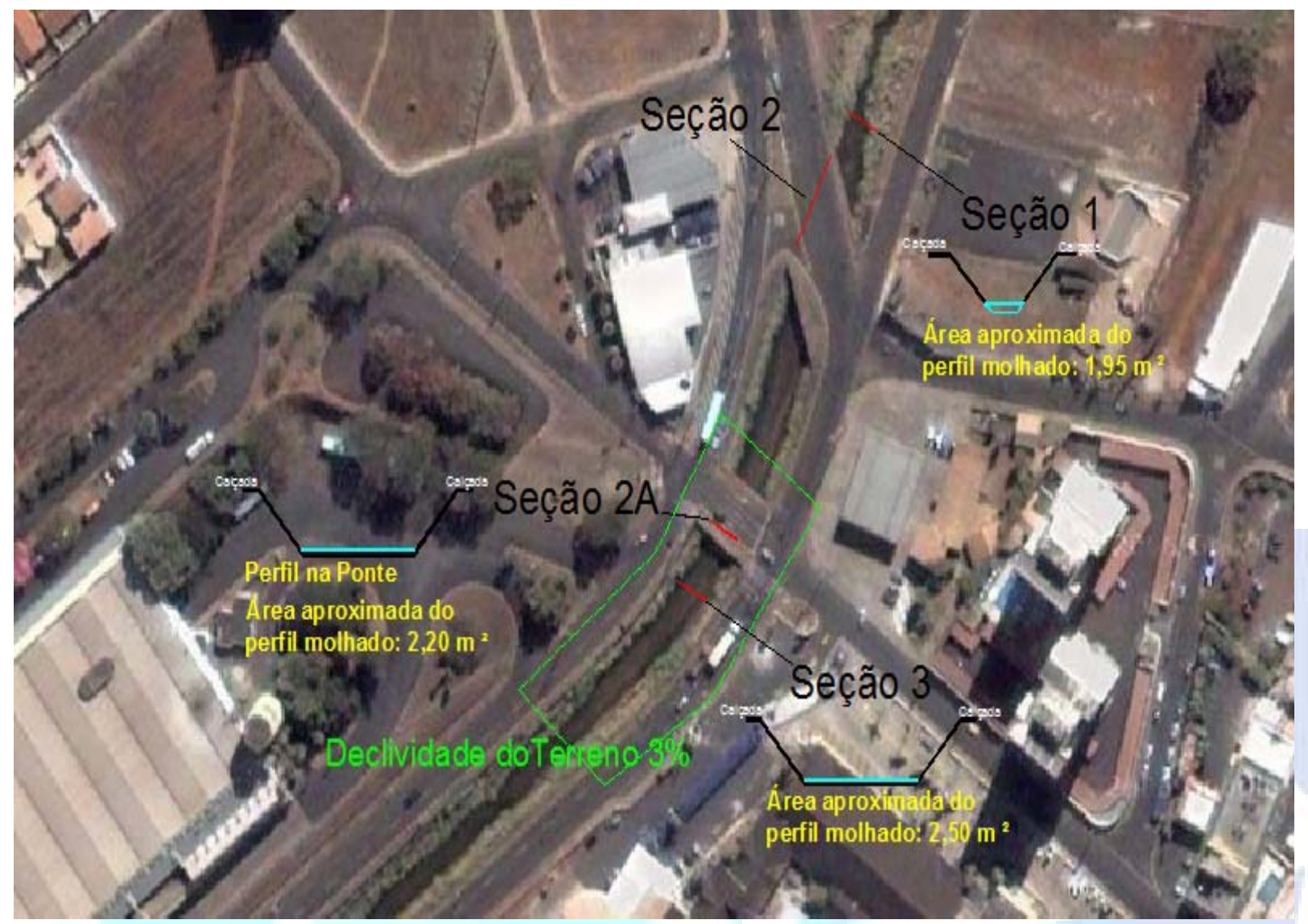

Figura 3. Representação das seções 1, 2, 2A e 3.

Fonte: Parize, 2010.

A seção do estudo 3, tem uma área aproximada do perfil molhado de $2,50 \mathrm{~m}^{2}$, a declividade desta região é de 3\%. Esta seção possui a maior área dentre as outras estudadas, o valor do cálculo da vazão de estiagem é de $3,8 \mathrm{~m}^{3} / \mathrm{s}$, comparando com a outra seção (1) a montante que possui uma área molhada de $1,95 \mathrm{~m}^{2}$ e vazão de $2,94 \mathrm{~m}^{3} / \mathrm{s}$. Foi considerado estes dois pontos por estarem entre o local que deságua o Córrego da Sevidão, por isso, há uma comparação entre as vazões.

Na Figura 4 está destacada em vermelho a atual concentração das galerias, já os círculos azuis demonstram a solução apresentada por este projeto (distribuição das galerias em uma área maior). 


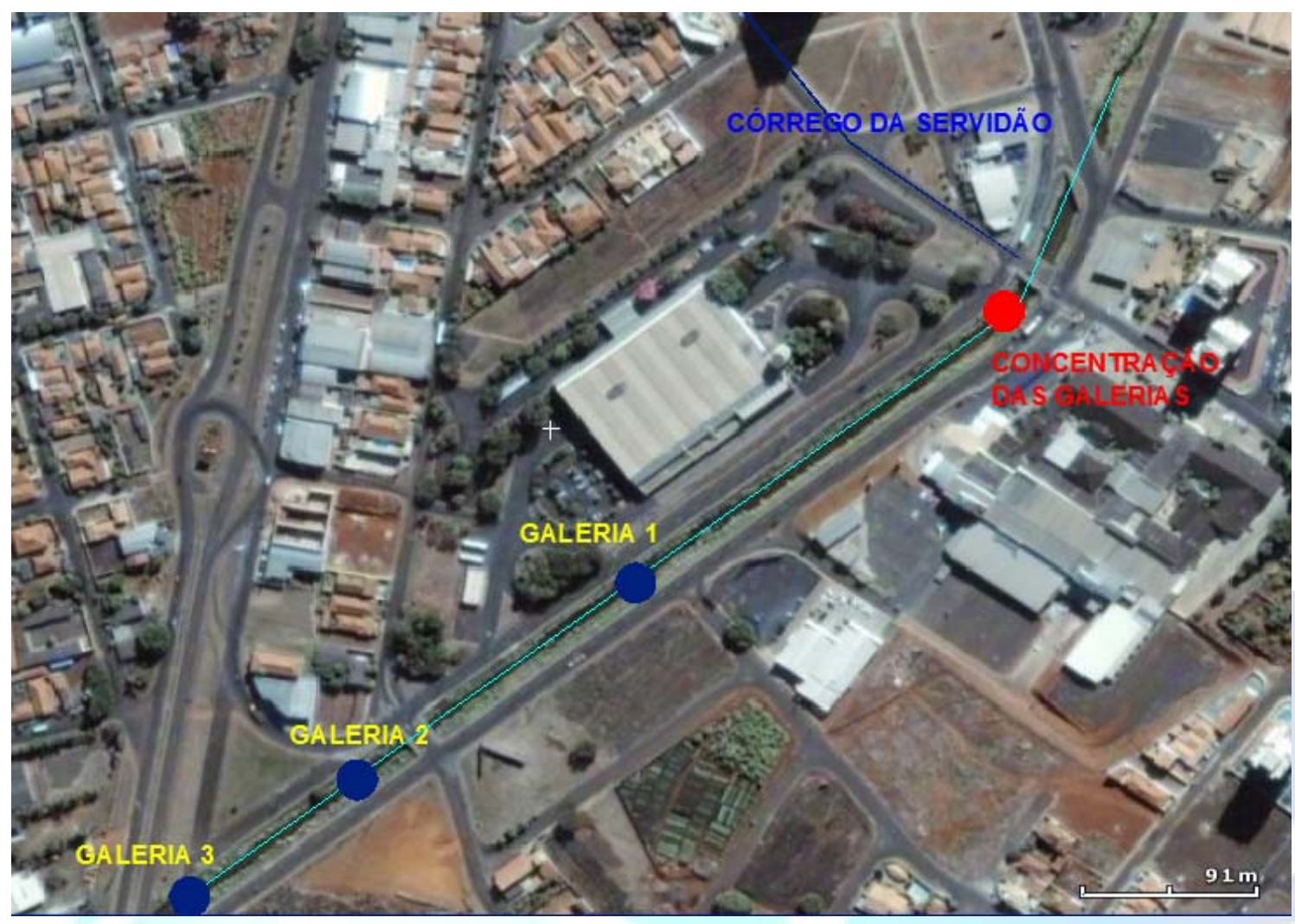

Figura 4. Demonstração de uma solução para o risco de enchente no Córrego do Ouro. Fonte: Parize, 2010.

\section{CONCLUSÕES}

Ao todo, 11 locais foram estudados nesta pesquisa, com destaque para um risco de enchente que foi mapeado em um local - Avenida Maria Antônia C. de Oliveira, próximo ao Terminal Rodoviário.

O problema da enchente deve-se ao fato de que diversas galerias pluviais deságuam em um único ponto (conforme a Figura 4 destaca em vermelho). Na montante deste ponto há o encontro de outro corpo d'água (Córrego da Servidão), que é um Córrego Subterrâneo. No verão, quando ocorrem grandes precipitações em uma escala de tempo pequena, o encontro dessas águas provoca uma explosão de volume. Somado a isso, a jusante deste problema possui uma ponte que retarda a velocidade do córrego, dificultando ainda mais o fluxo de vazão. Dessa forma, o córrego transborda.

Para tal problema a solução seria o redimensionamento da galeria pluvial, através de uma distribuição maior de área, estando à primeira galeria a uma distância de $240 \mathrm{~m}$, a segunda à $425 \mathrm{~m}$ e a terceira à $530 \mathrm{~m}$ do local do problema Figura 4. Portanto, o grande volume escoado no mesmo local será transferido para a jusante do problema, no caso, para a ponte.

Outra solução pertinente para este problema é o represamento das águas das chuvas, conhecido como piscinões, para que não haja uma concentração repentina no mesmo local.

Envolvendo medidas estruturais de maior porte, seria feito o redimensionamento da seção da ponte à jusante do risco, para facilitar o escoamento da água no corpo hídrico. Geralmente as obras de medidas estruturais são obras caras e complexas, tornando as obras de pequeno porte mais acessíveis ao órgão empreendedor. As obras de construções de pequenos piscinões têm como fim reter um pouco do volume da água da chuva. Outras medidas não convencionais seriam a criação de 
cisternas e reaproveitamento da água das chuvas para não provocar problemas futuros nas calhas dos rios.

A maior dificuldade encontrada para a realização deste trabalho é a falta de informações. Não há um registro histórico concreto sobre as enchentes, inundações (alagamentos) e ausência de estações meteorológicas a fim de que fosse promovida a monitoria dos locais que apresentam os riscos de problemas hidrometeorológicos entre outros.

Mapas e metodologia propostos neste trabalho representam uma estratégia de planejamento integrado entre setores públicos (trânsito, saneamento, urbanismo, saúde, entre outros), bem como entre diversas instituições ambientais (CETESB, Organizações não governamentais e empresas privadas).

Acerca da conscientização da população, é válido ressaltar que todos precisam de informações para enfrentar os desastres naturais, e tais instruções devem ser acompanhadas por políticas públicas de longo prazo e incentivos econômicos. Levando em conta que os atores envolvidos na gestão dos riscos ambientais (Defesa Civil, Corpo de bombeiros, Prefeitura, Universidades, Centro de pesquisas entre outros) devem manter uma comunicação contínua para prevenir e estabilizar as sociedades na gestão de riscos.

Portanto, é de extrema importância um monitoramento dessas áreas por parte da Prefeitura e Órgãos Públicos e uma avaliação geral, com o intuito de amenizar as conseqüências causadas pelas enchentes e inundações.

\section{AGRADECIMENTOS}

Os autores agradecem as Faculdades Integradas de Araraquara (FIAR) pelo incentivo que nos permitiu realizar este trabalho.

Também querem agradecer ao GPRA (Grupo de Pesquisas de Riscos Ambientais) pelos dados disponibilizados.

\section{REFERÊNCIA}

BRAGA, B.D.F. Gerenciamento urbano integrado em ambiente tropical. In: Seminário de Hidráulica Computacional Aplicada A Problemas de Drenagem Urbana. São Paulo, ABRH, 1994.

BRASIL. Lei n⿳0 6938, de 31 de Agosto de 1981. Art. 2, que estabelece qualidade ambiental propícia à vida. Disponível em: <http://www.planalto.gov.br/ccivil_03/leis/L6938compilada.htm> . Acesso em: 02 mai. 2010.

CANHOLI, A.P. Drenagem urbana e controle de enchentes. São Paulo: Ed. Oficinas de Textos, p.25-27, 31-32, 2005.

DAEE - Departamento de Águas e Energia Elétrica. Manual de cálculos das vazões máximas, médias e mínimas nas bacias hidrográficas do Estado de São Paulo, p.23- 29, 1994.

GOERL, R. F. Aprender Hidrologia para prevenção de desastres naturais. In: V SEMANA DE ENGENHARIA AMBIENTAL DAS FACULDADES INTEGRADAS DE ARARAQUARA, 5., 2010, Anais... Araraquara: 2010. 
HERRMANN, M. L de P. (Org). Atlas de Desastres Naturais do Estado de Santa Catarina. Florianópolis: IOESC, 2007.

KOBIYAMA, M; MENDONÇA, M; MORENO, D.A; MARCELINO, I.P.V; MARCELINO, V; GONÇALVES, E.F; BRAZETTI, L.L.P; GOERL, R; MOLLERI, G.S.F; RUDORFF, F.M.

Prevenção de Desastres Naturais Conceitos Básicos. Florianópolis: Ed. Organic Trading, 109p, 2006.

PARIZE, L. Estudo dos pontos críticos relacionados a problemas de riscos hidrometeorológicos do Município de Araraquara. 2010. 105 f. Trabalho de Conclusão de Curso (Graduação em Engenharia Ambiental) Faculdades Integradas de Araraquara (FIAR), Araraquara, 2010.

SNDC- SECRETARIA NACIONAL DEFESA CIVIL - Necessidade de fortalecimento da Defesa Civil no Brasil, 2009. Disponível em:

$<$ http://www.defesacivil.gov.br/noticias/noticia.asp?id=4732>. Acesso em: 10 abr. 2010.

TODINI, E. An operational decision support system for food risk mapping, forecasting and management. Urban Water, v. 1, p.131-143, 1999. 